Check for updates

Cite this: RSC Adv., 2017, 7, 21962

Received 17th February 2017

Accepted 9th April 2017

DOI: 10.1039/c7ra02016c

rsc.li/rsc-advances

\section{Synthesis and characterization of partially fluorinated aerogels and xerogels from environmentally-compatible precursors $\uparrow$}

\author{
Abby R. Jennings, ${ }^{a}$ Jena McCollum, ${ }^{a}$ Adam J. Wilkins, ${ }^{a}$ Stacy M. Manni ${ }^{b}$ \\ and Scott T. lacono (D)*a
}

A new fluorocyclic silane monomer was prepared from environmentally benign and commercially available starting reagents in two, high yielding steps. The monomer was characterized by multi-nuclear NMR $\left({ }^{1} \mathrm{H}\right.$, ${ }^{13} \mathrm{C},{ }^{19} \mathrm{~F}$, and $\left.{ }^{29} \mathrm{Si}\right)$. The monomer was used in the preparation of the first known fluorocyclic aerogels and xerogels. Due to the hydrophobic nature of the fluorocyclic monomer, a modified sol-gel synthesis was utilized in which a minimum amount of water was used. The mol\% of the fluorocyclic monomer was systematically varied in both types of silica gels and the effects on the properties of the aerogels and xerogels was analyzed by scanning electron microscopy, BET surface area measurements, differential scanning calorimetry, and thermogravimetric analysis. It was determined that in both aerogels and xerogels, increasing the mol\% of the fluorocyclic monomer resulted in condensed materials (i.e., pore collapse). Increased monomer concentration affected the gels thermal stability as the monomer is more susceptible to thermal decomposition than the silica gel. Pore collapse accelerates this effect as the condensed medium dissipates heat less efficiently.

\section{Introduction}

Since their discovery in the mid 1800's, silica gels have developed into a versatile class of materials with many uses including low dielectric, low refractive index, acoustic, and insulating materials. ${ }^{1-3}$ Over the last few decades, the syntheses of silica based gels by solution-gelation, or sol-gel, techniques has evolved and the ability to tailor the materials' properties through changing various reaction conditions is now better understood. ${ }^{4}$ The incorporation of other organic and inorganic derivatives within the silica sols to tune the gels properties has also become common practice, allowing silica based gels to find uses in more specialized realms. ${ }^{5-7}$

One such area is the implementation of fluorinated silica gels for low surface energy applications. ${ }^{\mathbf{8} 9}$ These low surface energy materials can be obtained by fluorinating the silica gel through different chemical transformations post-gelation or by adding a fluorinated reactive silane as a co-monomer during the sol-gel process. ${ }^{10,11}$ For example, Lermontov et al. acetylated amine terminated aerogels with the readily available reagent,

${ }^{a}$ Department of Chemistry, Chemistry Research Center, United States Air Force Academy, Colorado Springs, CO 80919, USA. E-mail: scott.iacono@usafa.edu

${ }^{b}$ Air Force Research Laboratory, Munitions Directorate, Ordinance Division, Energetic Materials Branch, Eglin Air Force Base, FL 32542, USA

$\dagger$ Electronic supplementary information (ESI) available: Detailed experimental procedures, ${ }^{1} \mathrm{H},{ }^{13} \mathrm{C},{ }^{19} \mathrm{~F}$, and ${ }^{29} \mathrm{Si}$ spectra, MS data, SEM images and BET plots. See DOI: $10.1039 / \mathrm{c} 7 \mathrm{ra02016c}$ methyl trifluoroacetate. ${ }^{12}$ The authors also synthesized a fluorinated reactive silane and employed it as a co-monomer with tetraethyl orthosilicate (TEOS) to prepare fluorinated aerogels and it was determined that the method of fluorine incorporation produced samples with different specific surface areas. It should be noted that a yield was not reported for the monomer that was synthesized. More recently, Jana et al. synthesized hydrophobic aerogels by adding the commercially available fluorinated reactive silane, dimethoxy-methyl(3,3,3-trifluoropropyl) silane, at different stages of the sol-gel synthesis. ${ }^{13}$ The authors determined that the point at which the fluorinated monomer was added had a significant effect on the hydrophobicity of the resulting aerogels.

As demonstrated above, the preparation of fluorinated solgels has relied heavily on the use of commercially available fluorinated materials, which offers limited structural and chemical variability. Furthermore, many of these readily available compounds incorporate the fluorinated component as a per-fluorinated carbon chain (PFC) of varying length and those possessing PFCs longer than six carbons in length are now known to have significant health and environmental hazards. ${ }^{\mathbf{1 4 5}}$ Alternatively, synthetic variations can be introduced by specially designing and synthesizing the fluorinated reactive silane monomers in house, however, they are typically plagued by multiple reaction steps, harsh conditions, and low to moderate yields. For instance, Shea and co-workers prepared a reactive fluorinated silane, containing a linear PFC, in three reaction steps, with an overall yield for the final product of $41 \%$. 
The authors utilized the monomer to prepare fluorinated xerogels. ${ }^{16}$

In this manuscript we describe the synthesis of a new fluorinated reactive silane monomer, 2 , that can be prepared in just two, high yielding steps, requiring simple, nonchromatographic purification techniques. The monomer was designed such that it utilized commercially available and benign starting materials, including the natural product, eugenol (EUG). Furthermore, the fluorinated component, perfluorocyclopentene (PFCP), used in the monomer's preparation is not known to possess the same hazards as its PFCs counterparts. After synthetic construction, 2 contains only three connected fluorocarbons, and thus is safe and biocompatible. The reactive monomer was used to prepare both aerogels and xerogels containing fluorocyclic functional groups. To the authors' knowledge, this is the first report of fluorocyclic aerogels and xerogels. The aerogels and xerogels were prepared such that the mol\% of 2 was varied from 0 to $100 \%$. A comparative study on the effects on the properties of the aerogels and xerogels with respect to the amount 2 were investigated through scanning electron microscopy (SEM), BET surface area measurements, differential scanning calorimetry (DSC), and thermogravimetric analysis (TGA). These results are presented and discussed in detail below.

\section{Experimental}

\section{Materials}

All reagents were purchased from Fischer Scientific and used as received unless stated otherwise. PFCP was purchased from SynQuest Laboratories. Karstedt's catalyst (platinum-divinyltetramethyldisiloxane complex in xylene) and triethoxysilane were obtained from Gelest. EUG was obtained from TCI and distilled prior to use. The triethylamine (TEA) was purchased from Fischer Scientific and distilled over calcium hydride prior to use. The ammonium hydroxide solution was obtained from Sigma Aldrich. The $\mathrm{CO}_{2}(\mathrm{~g})$ was purchased from Airgas.

\section{Instrumentation and characterization methods}

Gas chromatography mass spectrometry (GC-MS) samples were obtained using an Agilent Technologies 7890A GC system equipped with an Agilent Technologies 5975C Inert XL EI/CI MSD w/triple axis detector. The oven temperature was ramped from 70 to $250{ }^{\circ} \mathrm{C}$ at a rate of $20^{\circ} \mathrm{C} \mathrm{min}^{-1}$.

${ }^{1} \mathrm{H},{ }^{13} \mathrm{C}$, and ${ }^{19} \mathrm{~F}$ spectra were obtained on a Varian Mercury $400 \mathrm{MHz}$ Plus broadband spectrometer, and ${ }^{29} \mathrm{Si}$ NMR were recorded on a JEOL $500 \mathrm{MHz}$ spectrometer, under ambient temperature conditions. Chemical shifts were reported in parts per million $(\delta / \mathrm{ppm}) .{ }^{1} \mathrm{H}$ NMR was internally referenced to $\mathrm{CHCl}_{3}$ $\left(\delta\right.$ 7.24) or tetramethylsilane $(\delta 0.0),{ }^{13} \mathrm{C}$ NMR chemical shifts were reported relative to the center peak of the multiplet for $\mathrm{CDCl}_{3}(\delta 77.0)$, and ${ }^{19} \mathrm{~F}$ NMR was referenced to $\mathrm{CFCl}_{3}(\delta 0.0) .{ }^{29} \mathrm{Si}$ NMR was referenced to tetramethylsilane $\left(\begin{array}{ll}\delta & 0.0\end{array}\right)$ and was recorded with inverse-gated proton decoupling with a $3 \mathrm{~s}$ pulse delay. Coupling constants are reported in hertz $(\mathrm{Hz})$.
Supercritical fluid extraction was carried out with an EM Science E3100 large chamber supercritical dryer (SCD). The dryer was equipped with a PolyScience refrigeration/heating circulator, series 9102, digital temperature controller.

SEM was performed using an FEI Helios Nanolab Dual Beam. Samples were mounted on aluminium stubs with carbon tape and coated with gold-palladium. Aerogels were imaged at 5 $\mathrm{keV}$ and a working distance of $4 \mathrm{~mm}$ up to $150 \mathrm{k} \times$ magnification. Xerogels required an accelerating voltage of $15 \mathrm{keV}$ but maintained a $4 \mathrm{~mm}$ working distance and $150 \mathrm{k} \times$ magnification.

Nitrogen adsorption analysis was performed on ASAP 2020 (Micromeritics, Inc., GA) volumetric adsorption analyzer at $-196{ }^{\circ} \mathrm{C}$ with ultrahigh purity $(99.999+\%) \mathrm{N}_{2}$ gas over a relative pressure (equilibrium vapor pressure divided by saturation pressure) range of $10^{-6}$ to $\sim 0.996$. Prior to analysis, in order to remove any remaining solvent or physisorbed molecules, samples were degassed at $60^{\circ} \mathrm{C}$ for $8 \mathrm{~h}$ under vacuum until a pressure at or below $6 \mu \mathrm{m} \mathrm{Hg}$. Samples of known mass were placed in glass sample tubes of known volume (both at room temperature and $-196^{\circ} \mathrm{C}$ ) and a conversion shown in eqn (1) where CFS is the cold free space (volume) of the tube with sample at $-196{ }^{\circ} \mathrm{C}, \mathrm{CFS}_{\text {empty }}$ is the cold free space (volume) of the empty tube at $-196{ }^{\circ} \mathrm{C}, m$ is the mass of the sample at room temperature, 3.533 is a conversion factor between room temperature and $-196{ }^{\circ} \mathrm{C} ; \rho$ is the density of the sample, was used to account for the sample volume in the sample tube. The densities of the aerogel samples used in eqn (1) were 1.826, 1.7, 1.6, 1.516, and $1.411 \mathrm{~g} \mathrm{~mL}^{-1}$ for the 0,20 , 30,50 , and $100 \mathrm{~mol} \%$ aerogel samples, respectively.

$$
\mathrm{CFS}=\mathrm{CFS}_{\mathrm{empty}}-(3.533 m) / \rho
$$

The sample was then placed under vacuum and immersed in a Dewar of liquid nitrogen for analysis. A fixed volume of nitrogen gas was dosed into the sample tube, equilibrium was established and the pressure and volume of adsorbed gas was recorded. This process continued over the entire range of relative pressures $\left(10^{-6}\right.$ to $\left.\sim 0.996\right)$ and was followed by desorption of the adsorbed $\mathrm{N}_{2}$ molecules. These measurements resulted in a nitrogen adsorption isotherm (quantity adsorbed (i.e., $\mathrm{cm}^{3}$ STP per $\mathrm{g}$ ) as a function of relative pressure (i.e., $\left.p / p_{0}\right)$ ) which shows the volume of $\mathrm{N}_{2}$ adsorbed on the surface of the material as a function of the relative pressure range. The BET specific surface area is based on the Brunauer Emmet Teller model of adsorption and is calculated from the nitrogen adsorption isotherm within the relative pressure range of 0.05$0.3 .^{17,18}$ The single-point pore volume (cumulative volume of micropores, under $2 \mathrm{~nm}$, and mesopores, 2-50 nm) was determined from the quantity of adsorbed nitrogen at a relative pressure of 0.98 .

Differential scanning calorimetry was performed using a TA Instruments SDT model Q600. Samples were loaded into alumina crucibles and held at room temperature for $10 \mathrm{~min}$ under flowing $\mathrm{Ar}$ gas. The temperature was then ramped at $5{ }^{\circ} \mathrm{C}$ $\min ^{-1}$ from 30 to $700{ }^{\circ} \mathrm{C}$ under argon.

Thermogravimetric analysis was performed using a TA Q500 TG analyser. Samples were loaded onto platinum sample pans and held at room temperature for 10 min under flowing 
nitrogen gas. The temperature was then ramped at $5{ }^{\circ} \mathrm{C} \mathrm{min}^{-1}$ from 30 to $900{ }^{\circ} \mathrm{C}$ under nitrogen.

\section{Synthetic procedures}

Synthesis of 4-allyl-1-[2-(4-allyl-2-methoxy-phenoxy)-3,3,4, 4,5,5-hexafluoro-cyclopenten-1-yl] oxy-2-methoxy-benzene (1). A $50 \mathrm{~mL}$ round bottom flask, equipped with a stir bar, was charged with dimethylformamide (DMF, $6.0 \mathrm{~mL})$, TEA $(1.10 \mathrm{~mL}$, $7.94 \mathrm{mmol})$, and eugenol $(1.15 \mathrm{~mL}, 7.43 \mathrm{mmol})$. The flask was sealed and then PFCP (1.00 mL, $7.45 \mathrm{mmol})$ was added, using a syringe. The solution was stirred at room temperature for $30 \mathrm{~min}$. GC-MS was used to verify the conversion to intermediate compound. More eugenol (1.15 mL, $7.43 \mathrm{mmol}$ ) and $\mathrm{Cs}_{2} \mathrm{CO}_{3}(1.25 \mathrm{~g}, 3.84 \mathrm{mmol})$ were added and the solution was gently heated $\left(50{ }^{\circ} \mathrm{C}\right)$ overnight. GC-MS was employed to confirm the conversion of the intermediate to $\mathbf{1}$. The solution was then washed with brine and the organics were extracted with ether, dried with $\mathrm{MgSO}_{4}$, vacuum filtered, and concentrated under reduced pressure. The concentrated filtrate was added to a silica gel pad and then washed with a $3: 1$ DCM : hexane solution $(200 \mathrm{~mL})$. All volatiles were removed under reduced pressure. Compound 1 was obtained as a clear, pale yellow viscous liquid (1.75 g, 94\%). ${ }^{1} \mathrm{H}$ NMR $\left(\mathrm{CDCl}_{3}, 400\right.$ $\mathrm{MHz}): \delta 6.76\left(\mathrm{~d}\right.$, aromatic, $\left.2 \mathrm{H},{ }^{3} J_{\mathrm{HH}}=8.4 \mathrm{~Hz}\right), 6.56-6.53(\mathrm{~m}$, aromatic, $4 \mathrm{H}$ ), 5.95-5.86 (m, vinyl, $2 \mathrm{H}), 5.10-5.02$ (m, vinyl, $4 \mathrm{H}$ ), $3.73\left(\mathrm{~s},-\mathrm{OCH}_{3}, 6 \mathrm{H}\right), 3.30\left(\mathrm{~d}, \mathrm{CH}_{2}=\mathrm{CHCH}_{2} \mathrm{C}-, 4 \mathrm{H},{ }^{3} J_{\mathrm{HH}}=6.6\right.$ $\mathrm{Hz}) .{ }^{13} \mathrm{C} \mathrm{NMR}\left(\mathrm{CDCl}_{3}, 100 \mathrm{MHz}\right): \delta 149.4$ (aromatic C), 141.8 (aromatic C), 137.8 (aromatic C), $137.0\left(\mathrm{CH}_{2}=\mathrm{CHCH}_{2}-\right), 120.1$ (aromatic $\mathrm{CH}$ ), 118.2 (aromatic $\mathrm{CH}), 116.0\left(\mathrm{CH}_{2}=\mathrm{CHCH}_{2}{ }^{-}\right.$), 112.5 (aromatic $\mathrm{CH}$ ), $55.4\left(-\mathrm{OCH}_{3}\right), 39.8\left(\mathrm{CH}_{2}=\mathrm{CHCH}_{2}{ }^{-}\right) .{ }^{19} \mathrm{~F}$ NMR $\left(\mathrm{CDCl}_{3}, 376 \mathrm{MHz}\right): \delta-114.3\left(\mathrm{t}, 4 \mathrm{~F},{ }^{3} J_{\mathrm{FF}}=4.4 \mathrm{~Hz}\right),-130.3$ (p, $2 \mathrm{~F},{ }^{3} J_{\mathrm{FF}}=4.2 \mathrm{~Hz}$ ).

Synthesis of triethoxy-[3-[4-[3,3,4,4,5,5-hexafluoro-2-[2-methoxy4-(3-triethoxysilylpropyl)phenoxy]cyclopenten-1-yl]oxy-3methoxy-phenyl]propyl]silane (2). A $25 \mathrm{~mL}$ round bottom flask, equipped with a magnetic stir bar, was charged with $1(0.22 \mathrm{~g}$, $0.44 \mathrm{mmol}$ ) and 1 drop of Karstedt's catalyst. The solution was stirred under $\mathrm{N}_{2}$, and then the triethoxysilane $(0.20 \mathrm{~mL}, 1.08$ mmol) was added, dropwise, using a syringe. The solution was stirred, under $\mathrm{N}_{2}$, at room temperature, overnight. A ${ }^{1} \mathrm{H}$ NMR was taken to verify the conversion of reactants to products. All volatiles were removed under reduced pressure with low heat $\left(35-40{ }^{\circ} \mathrm{C}\right)$. Compound 2 was obtained as a clear light yellow, viscous liquid $(0.34 \mathrm{~g}, 92 \%) .{ }^{1} \mathrm{H} \mathrm{NMR}\left(\mathrm{CDCl}_{3}, 400 \mathrm{MHz}\right): \delta 6.98$ (d, aromatic C, $\left.2 \mathrm{H},{ }^{3} \mathrm{~J}_{\mathrm{HH}}=7.6 \mathrm{~Hz}\right), 6.54-6.53(\mathrm{~m}$, aromatic C, $4 \mathrm{H}), 3.80\left(\mathrm{q},-\mathrm{OCH}_{2} \mathrm{CH}_{3}, 12 \mathrm{H},{ }^{3} J_{\mathrm{HH}}=6.2 \mathrm{~Hz}\right), 3.69(\mathrm{~s}, 6 \mathrm{H}$, $\left.-\mathrm{OCH}_{3}\right), 2.52\left(\mathrm{t},-\mathrm{SiCH}_{2} \mathrm{CH}_{2} \mathrm{CH}_{2}-, 4 \mathrm{H},{ }^{3} \mathrm{~J}_{\mathrm{HH}}=7.6 \mathrm{~Hz}\right), 1.65(\mathrm{p}$, $\left.-\mathrm{SiCH}_{2} \mathrm{CH}_{2} \mathrm{CH}_{2}-, 4 \mathrm{H},{ }^{3} J_{\mathrm{HH}}=7.9 \mathrm{~Hz}\right), 1.20\left(\mathrm{t},-\mathrm{OCH}_{2} \mathrm{CH}_{3}, 18 \mathrm{H}\right.$, $\left.{ }^{3} J_{\mathrm{HH}}=6.8 \mathrm{~Hz}\right), 0.63-0.59\left(\mathrm{~m},-\mathrm{SiCH}_{2} \mathrm{CH}_{2} \mathrm{CH}_{2}-, 4 \mathrm{H}\right) .{ }^{13} \mathrm{C} \mathrm{NMR}$ $\left(\mathrm{CDCl}_{3}, 100 \mathrm{MHz}\right): \delta 149.3$ (aromatic C), 141.5 (aromatic C), 140.1 (aromatic C), 120.0 (aromatic $\mathrm{CH}$ ), 118.1 (aromatic $\mathrm{CH}$ ), 112.5 (aromatic $\mathrm{CH}), 58.3\left(-\mathrm{OCH}_{2} \mathrm{CH}_{3}\right), 55.5\left(-\mathrm{OCH}_{3}\right), 38.9$ $\left(-\mathrm{SiCH}_{2} \mathrm{CH}_{2} \mathrm{CH}_{2}-\right), 24.9\left(-\mathrm{SiCH}_{2} \mathrm{CH}_{2} \mathrm{CH}_{2}-\right), 18.2\left(-\mathrm{OCH}_{2} \mathrm{CH}_{3}\right)$, $10.0\left(-\mathrm{SiCH}_{2} \mathrm{CH}_{2} \mathrm{CH}_{2}-\right) .{ }^{19} \mathrm{~F} \mathrm{NMR}\left(\mathrm{CDCl}_{3}, 376 \mathrm{MHz}\right): \delta-114.3(\mathrm{t}$, $4 \mathrm{~F}),-130.3$ to $-130.4(\mathrm{~m}, 2 \mathrm{~F}) .{ }^{29} \mathrm{Si} \mathrm{NMR}\left(\mathrm{CDCl}_{3}, 99 \mathrm{MHz}\right)$ : $\delta-45.1$.
Preparation of sol-gel catalyst. A catalyst was prepared by combining deionized water (DIW, $50.0 \mathrm{~mL}$ ), ammonium fluoride (0.93 g, $26.5 \mathrm{mmol})$, and ammonium hydroxide ( 28-30\% $\mathrm{NH}_{3}$ in water, $11.6 \mathrm{~mL}, 172 \mathrm{mmol}$ ) in a volumetric flask.

Synthesis of sols containing $\mathbf{0}-\mathbf{3 0} \mathbf{~ m o l} \%$ of 2 . For each $\mathrm{mol} \%$ formulation, the total amount of reactive silane, TEOS and 2, were held constant at $13.0 \mathrm{mmol}$. A $50 \mathrm{~mL}$ beaker equipped, with a stir bar, was charged with absolute ethanol (Abs. EtOH, $2.4 \mathrm{~mL}$ ), TEOS, and where appropriate, 2. In a separate container, a solution consisting of absolute EtOH $(5.5 \mathrm{~mL})$, the catalyst solution $\left(8.0 \times 10^{-2} \mathrm{~mL}\right)$, and DIW was prepared. The amount of water was determined using eqn (2).

$$
V_{\mathrm{H}_{2} \mathrm{O}}(\mathrm{mL})=[(4 x+6 y)(18.02)]
$$

where $V$ is the volume of water, $x$ is the total moles of TEOS and $y$ is the total moles of 2 . This solution was then added, with stirring to the $50 \mathrm{~mL}$ beaker. The sol solutions were stirred at room temperature for $10 \mathrm{~min}$.

Synthesis of sols containing 50 and $100 \mathrm{~mol} \%$ of 2 . The same procedure was used to synthesize the 50 and $100 \mathrm{~mol} \%$ sols except that the amount of catalyst solution was increased to 0.16 $\mathrm{mL}$ and the amount of water employed was determined using eqn (3).

$$
V_{\mathrm{H}_{2} \mathrm{O}}(\mathrm{mL})=[(4 x+6 y)(18.02)]-0.16
$$

where $V$ is the volume of water, $x$ is the total moles of TEOS and $y$ is the total moles of 2 . The sol solutions were stirred at room temperature for $48 \mathrm{~h}$.

Preparation and aging of the sol-gels. Moulds were prepared from NORM-JECT $30 \mathrm{~mL}$ polypropylene syringes with an inner diameter or $22.9 \mathrm{~mm} .{ }^{19}$ The sol solutions were poured into the molds, covered with parafilm, and allowed to gel/age at room temperature. After solidifying, the gels were carefully removed from the syringes into beakers and completely submerged with abs. EtOH. The abs. EtOH was replaced every 16-24 h over a four day period. The gels were removed from the beaker and cut in half. One half of the sol-gel was placed in the SCD to yield the aerogel, while the other was dried under ambient conditions and then reduced pressure at $80{ }^{\circ} \mathrm{C}$ for 7 d to obtain a xerogel.

Method for supercritical drying. The SCD was precooled to $14{ }^{\circ} \mathrm{C}$. The sol-gel to be dried was placed in a weighted plastic capsule with holes in the bottom of one end and the top of the other. The SCD was filled with $\mathrm{CO}_{2}$ (l) until the capsule was completely submerged. The sol-gel was allowed to soak for $1 \mathrm{~h}$ and then the chamber was partially drained and then re-filled. This was repeated three more times, ensuring the abs. EtOH was completely exchanged with $\mathrm{CO}_{2}$ (l). Next, the temperature was increased at a rate of $5{ }^{\circ} \mathrm{C} / 15 \mathrm{~min}$, until the chamber surpassed $35^{\circ} \mathrm{C}$ and 1200 psi. After the chamber had been at 1200 psi and above $35^{\circ} \mathrm{C}$ for approximately $10 \mathrm{~min}$, the pressure was slowly released over a $16 \mathrm{~h}$ period. After reaching ambient pressure, the aerogel was then removed from the chamber and capsule. 


\section{Results and discussion}

\section{Monomer and sol-gel synthesis}

As previously mentioned, one of the objectives of this research was to obtain fluorinated aerogels and xerogels that utilized fluorocyclic functional groups. Having already demonstrated that PFCP is reactive towards a number of different nucleophiles, it was an ideal choice for the synthesis of a reactive silane monomer that could be used in the synthesis of the solgel materials. ${ }^{20}$ In this particular instance, EUG, which is an essential oil extracted from natural sources such as clove oil, cinnamon, nutmeg, basil, and bay leaf, was chosen as the desired nucleophile.

The synthesis of 4-allyl-1-[2-(4-allyl-2-methoxy-phenoxy)3,3,4,4,5,5-hexafluoro-cyclopenten-1-yl] oxy-2-methoxy-benzene, $\mathbf{1}$, is shown in Scheme 1. Initially, one equivalent of EUG is reacted with a slight excess of PFCP, in the presence of TEA. The reaction is monitored by GC-MS and once the in situ conversion of the reactants to the mono-substituted intermediate (1a) is verified, a second equivalent of EUG is added and the reaction mixture is gently heated in the presence of $\mathrm{Cs}_{2} \mathrm{CO}_{3}$. It should be noted that even if an excess of EUG is used in step 1 of the synthesis, only 1a is obtained, even when heat is employed. The conversion of 1a into the final product is also monitored by GCMS (Fig. S3 $\dagger$ ) and after simple purification through a silica gel pad, $\mathbf{1}$ is obtained in high yield, as a clear, faint yellow, viscous liquid.

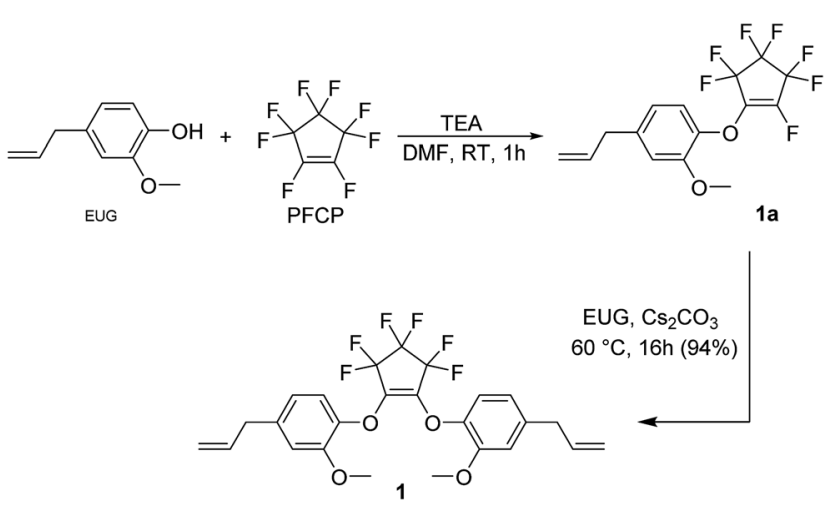

Scheme 1 Synthesis of 1.

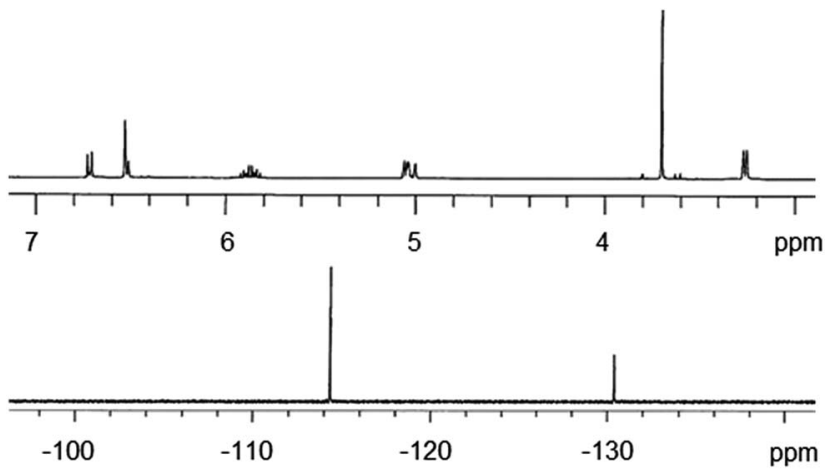

Fig. $1{ }^{1} \mathrm{H}$ NMR $\left(400 \mathrm{MHz}, \mathrm{CDCl}_{3}\right)$ and ${ }^{19} \mathrm{~F} \mathrm{NMR}\left(376 \mathrm{MHz}, \mathrm{CDCl}_{3}\right)$ of 1.
Compound 1 was fully characterized using multinuclear NMR (Fig. S4-S6†) and the ${ }^{1} \mathrm{H}$ and ${ }^{19}$ F NMR are shown in Fig. 1. The hydroxyl proton of EUG is reported at $5.73 \mathrm{ppm}(400 \mathrm{MHz}$, $\mathrm{CDCl}_{3}$ ). Thus, the ${ }^{1} \mathrm{H}$ spectrum shown in Fig. 1 appears to indicate the successful nucleophilic addition of EUG to the PFCP ring. Being that the addition of one or two equivalents of EUG would produce an identical spectrum, ${ }^{21}{ }^{19} \mathrm{~F}$ NMR analysis of $\mathbf{1}$ is required to verify the addition of two equivalents of EUG. In addition to disappearance of the vinylic fluorine signals of the PFCP starting material, two signals appear in a $2: 1$ ratio providing conformation of the successful synthesis of 1 .

After obtaining 1, it was reacted with a slight excess of triethoxysilane utilizing a hydrosilylation reaction, in the presence of a platinum catalyst, Scheme 2 . Compound 2 is obtained as a clear, light yellow, viscous liquid, in high yield, requiring no purification. Compound 2 was fully characterized using multinuclear NMR (Fig. S7-S10 $)$ ). Fig. 2 shows the ${ }^{1} \mathrm{H}$ and ${ }^{29} \mathrm{Si}$ NMR of 2 . In comparing the ${ }^{1} \mathrm{H}$ NMR spectrum of 1 with 2 , it is evident that the hydrosilylation reaction has taken place. Upon addition of the triethoxysilane to 1 , the signals due to the vinyl protons of 1 and the silane $(-\mathrm{Si} H)$ disappear.

Additionally, new signals at 2.52, 1.65, and 0.63-0.59 ppm appear as a result of alkyl bond formation $\left(-\mathrm{CH}_{2} \mathrm{CH}_{2} \mathrm{CH}_{2} \mathrm{Si}\right)$. The ${ }^{29} \mathrm{Si}$ NMR of 2 shows one signal at $-45.1 \mathrm{ppm}$ and is assigned to the silicon atoms within the terminal triethoxysilane groups $\left(-\mathrm{Si}(\mathrm{OEt})_{3}\right)$. It should be noted that the fluorine NMR of 2

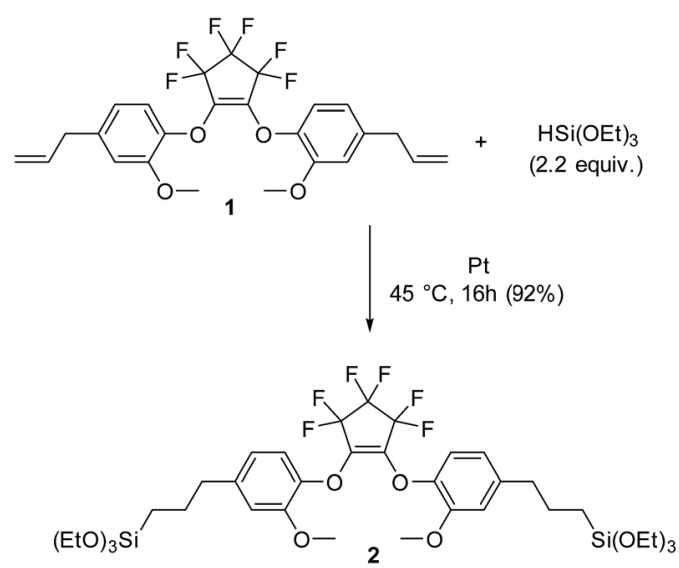

Scheme 2 Synthesis of 2 .

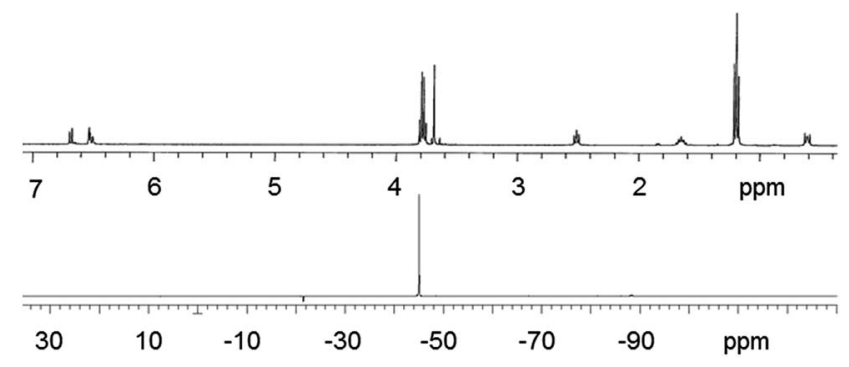

Fig. $2{ }^{1} \mathrm{H} \mathrm{NMR}\left(400 \mathrm{MHz}, \mathrm{CDCl}_{3}\right)$ and ${ }^{29} \mathrm{Si} \mathrm{NMR}\left(99 \mathrm{MHz}, \mathrm{CDCl}_{3}\right)$ of 2. 
appeared the same as that obtained for $\mathbf{1}$ (Fig. S6 and S9†), indicating that $\mathbf{1}$ is stable towards the hydrosilylation reaction.

After obtaining 2, it was used in the sol-gel synthesis of aerogels and xerogels. The sol-gels were prepared using a slightly modified procedure. During the initial studies, it was determined that the hydrophobicity of 2 , as a result of the incorporation of PFCP, was great enough that only the minimum amount of water could be used during the preparation of the gels. As a result, eqn (2) was used to calculate the stoichiometric amount of water required for each formulation up to $30 \mathrm{~mol} \%$. Moreover, in those sol-gel formulations in which $50 \mathrm{~mol} \%$ or greater of 2 was employed, more catalyst was required to obtain solidified gels within a reasonable time frame, i.e. $<1$ week. Thus, the water added as a result of the catalyst could not be ignored, and eqn (3) was used to calculate the amount of water needed. Once the sol-gels were solidified and aged, each formulation was split into two pieces. One portion was dried under super critical conditions to obtain the aerogels, while the other was dried under ambient conditions to obtain the xerogels. Table 1 lists the reagents and amounts used in each formulation of the sol-gel.

\section{Sol-gel characterization}

Fig. 3 shows SEM images of aerogels with TEOS only, 20 and 30 mol\% of 2. Microstructural pores are evident in the TEOS only 20 and $30 \mathrm{~mol} \%$ samples show decreasing porosity, and no porosity is observed for 50 and $100 \mathrm{~mol} \%$ loadings. This indicates that pores have collapsed between 30 and $50 \mathrm{~mol} \%$ loading. SEMs of aerogels with 50 and 100 mol\% loading of 2

Table 1 Reagents and amounts used in the preparation of the solgels

\begin{tabular}{llllll}
\hline \multicolumn{5}{c}{ Formulation } \\
\cline { 2 - 6 } & 0 mol\% & $20 \mathrm{~mol} \%$ & $30 \mathrm{~mol} \%$ & $50 \mathrm{~mol} \%$ & $100 \mathrm{~mol} \%$ \\
\hline TEOS $(\mathrm{mL})$ & 3.00 & 2.32 & 2.03 & 0.71 & - \\
$2(\mathrm{~g})$ & - & 2.16 & 3.23 & 2.65 & 5.39 \\
$\mathrm{H}_{2} \mathrm{O}(\mathrm{mL})$ & 0.97 & 1.03 & 1.08 & 0.42 & 0.54 \\
Cat. (mL) & 0.08 & 0.08 & 0.08 & 0.16 & 0.16
\end{tabular}
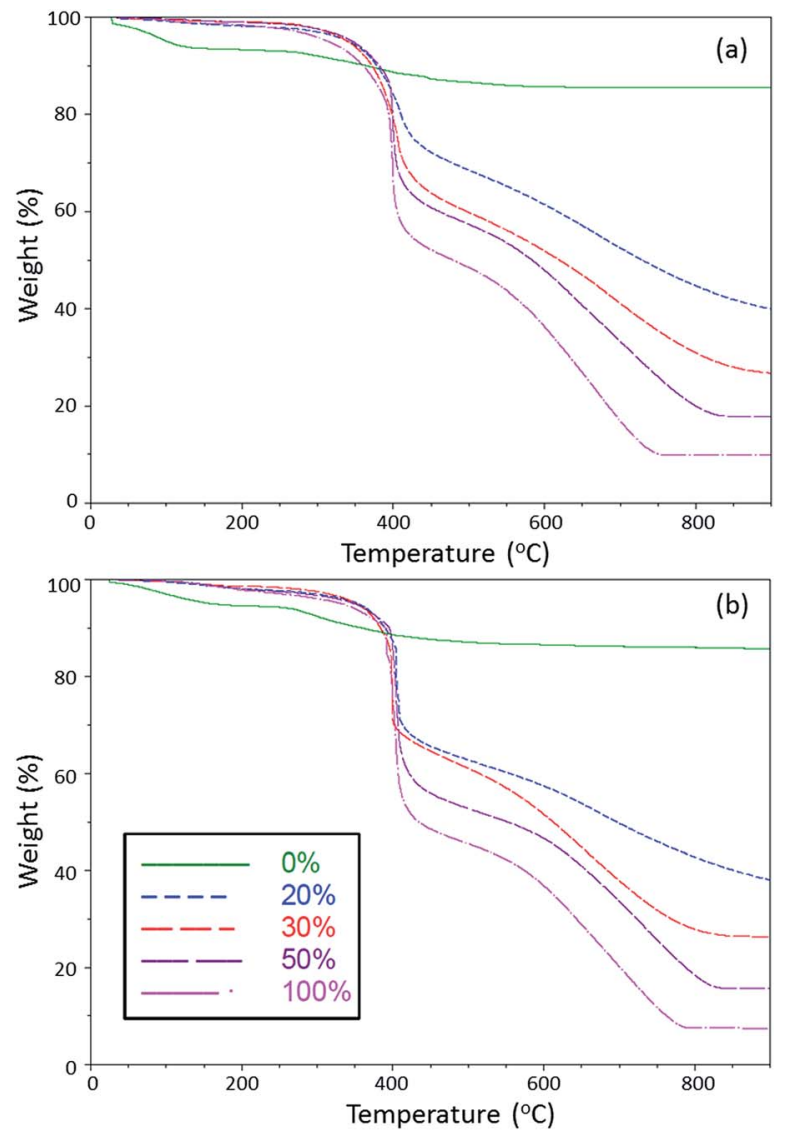

Fig. 4 Mass loss traces for the aerogels (a) and xerogels (b) with mol\% loadings of 2 .

are presented in Fig. S11. $\dagger$ The xerogels had no porous structure regardless of 2 loading (Fig. S12 $\dagger$ ).

In order to validate SEM findings, surface area measurements were performed. Plots from these measurements are shown in Fig. S13. $\dagger$ Surface area decreases dramatically in the aerogel samples from 0 to $30 \mathrm{~mol} \%$ loading. The surface areas for the 0,20 , and $30 \mathrm{~mol} \%$ aerogels were found to be $861.8 \pm$ $5.0,69.2 \pm 0.3$, and $15.6 \pm 0.1 \mathrm{~m}^{2} \mathrm{~g}^{-1}$, respectively. Aerogels with 50 and 100 mol\% loading had no measurable surface area by this method. These materials are low surface area materials without any evidence of micro- or meso-pores, indicating the
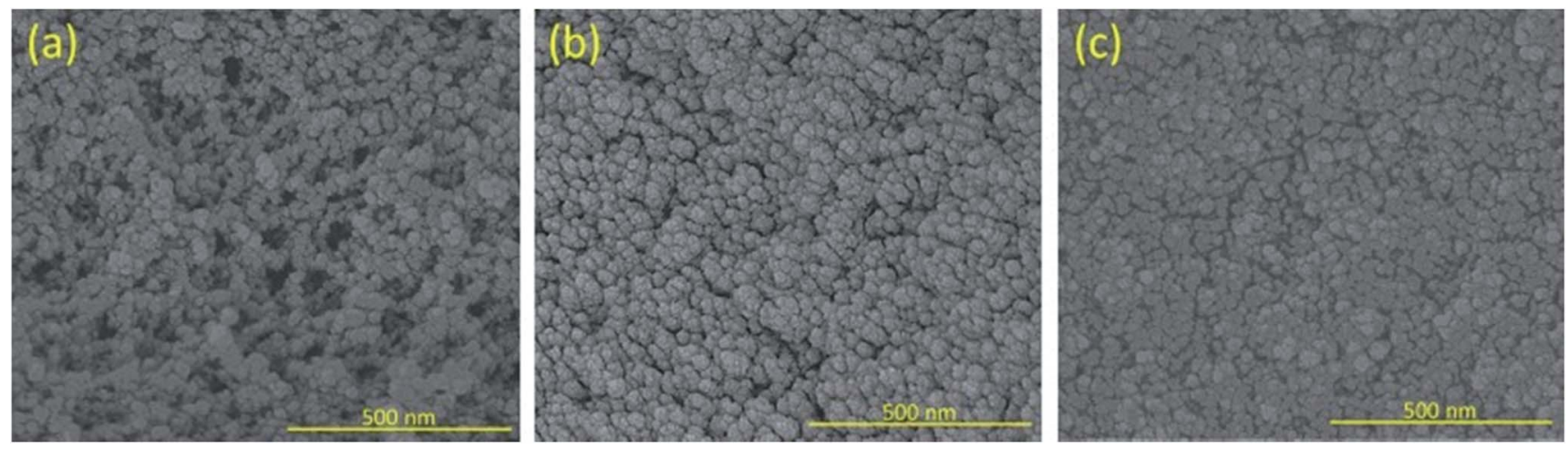

Fig. 3 SEM images of aerogels with TEOS only (a), $20 \mathrm{~mol} \%$ (b), and $30 \mathrm{~mol} \%$ (c) of 2. 
resulting pores may have collapsed. This confirms that addition of the fluorine-containing silane precursor 2 beyond $30 \mathrm{~mol} \%$ loading causes pore collapse due to its inherent hydrophobic nature, resulting in a dense sample that behaves as a xerogel.

Fig. 4 shows the mass loss traces for the aerogels (a) and xerogels (b). All samples show a slight mass loss, up to $150^{\circ} \mathrm{C}$, and are attributed to the evaporation of adsorbed water and ethanol. Within the TEOS only aerogels and xerogels, there is an additional mass loss event that occurs above $250{ }^{\circ} \mathrm{C}$ and is assigned to the loss of physisorbed water and the dehydration of free silanol sites. $^{22,23}$ If the overall mass loss for the aerogel and xerogel samples are corrected for the adsorbed volatile species, unreacted silanol sites, and the percent of the degradable component of $\mathbf{2}$ is taken into account $(\sim 80 \%)$, then the overall mass losses for the aerogel and xerogel samples fall within range of what one might expect for each sample. For example, the expected mass loss for the $20,30,50$, and $100 \mathrm{~mol} \%$ samples would be $54,64,78$, and $94 \%$, respectively. Furthermore, the use of PFCP based monomer 2 in the sol-gel formulations increases the thermal stability with respect to other known fluorinated gels in which thermal analysis was performed. ${ }^{24,25}$ This indicates that the use of a fluorocyclic functional group versus a PFC has the potential to enhance the thermal stability of the resulting material.

Fig. 5 shows the DSC traces for the aerogels (a) and xerogels (b). Thermal analysis shows that all samples containing 2 have an exothermic onset $\left(T_{\mathrm{O}}\right)$ around $395^{\circ} \mathrm{C}$. The DSC shows that above
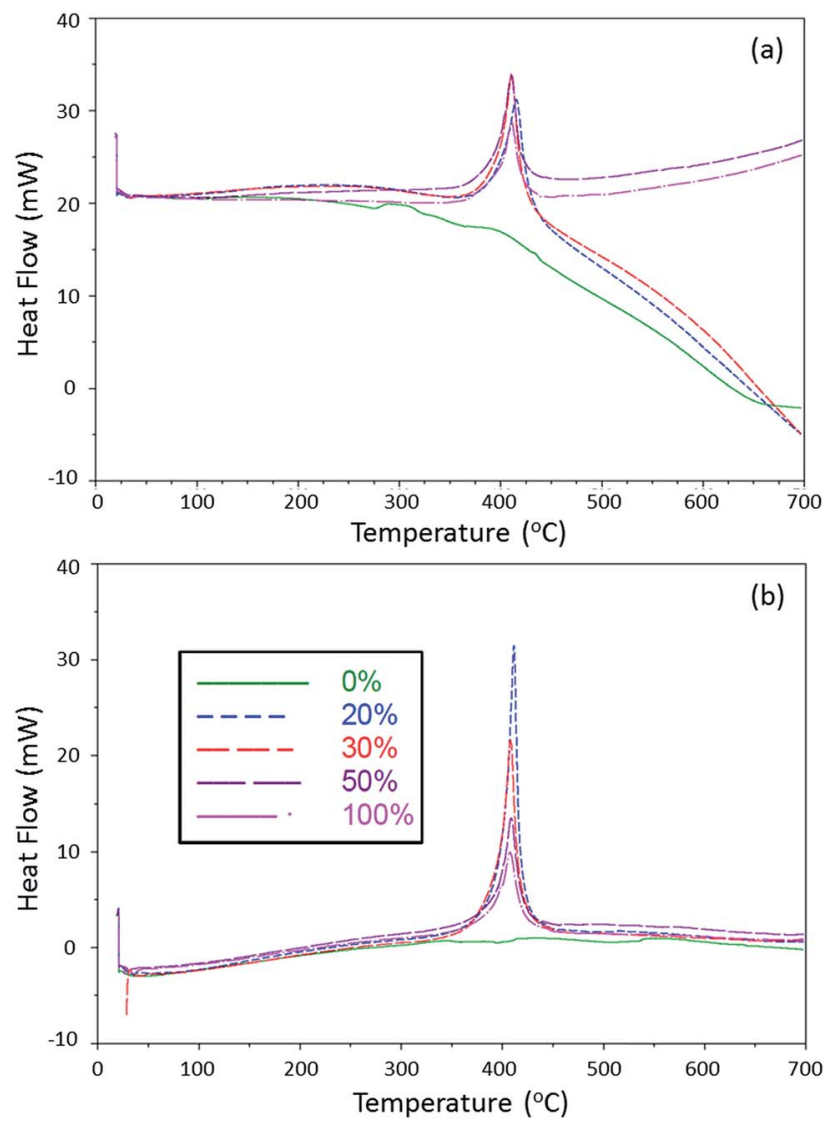

Fig. 5 Heat flow traces for the aerogels (a) and xerogels (b) with mol\% loadings of 2 .
Table 2 Summary of characterization data for sol-gels

\begin{tabular}{llllllll}
\hline $\begin{array}{l}\text { Sample } \\
(\mathrm{mol} \% \text { 2) }\end{array}$ & $\begin{array}{l}\text { Surface area } \\
\left(\mathrm{m}^{2} \mathrm{~g}^{-1}\right)\end{array}$ & $\begin{array}{l}T_{\mathrm{O}}{ }^{b} \\
\left({ }^{\circ} \mathrm{C}\right)\end{array}$ & $\begin{array}{l}\Delta H^{c} \\
\left(\mathrm{~J} \mathrm{~g}^{-1}\right)\end{array}$ & $T_{\mathrm{D}}{ }^{d}\left({ }^{\circ} \mathrm{C}\right)$ & $\begin{array}{l}\text { Sample } \\
(\mathrm{mass} \% 2)\end{array}$ & $\begin{array}{l}\text { Mass } \\
\operatorname{loss}^{e}(\%)\end{array}$ \\
\hline \multirow{2}{*}{ Aerogels } & 0 & $861.8 \pm 5.0$ & - & - & - & 0 & 14 \\
& 20 & $69.2 \pm 0.3$ & 394 & 457 & 371 & 50 & 59 \\
& 30 & $15.6 \pm 0.1$ & 396 & 501 & 380 & 63 & 72 \\
& 50 & $\mathrm{~N}^{a}$ & 396 & 576 & 393 & 80 & 82 \\
& 100 & $\mathrm{~N} / \mathrm{A}^{a}$ & 397 & 575 & 393 & 100 & 90 \\
Xerogels & 0 & $\mathrm{~N} / \mathrm{A}^{a}$ & - & - & - & 0 & 14 \\
& 20 & $\mathrm{~N}^{a}$ & 400 & 501 & 371 & 50 & 62 \\
& 30 & $\mathrm{~N}^{a}$ & 395 & 556 & 390 & 63 & 71 \\
& 50 & $\mathrm{~N}^{a}$ & 396 & 652 & 397 & 80 & 84 \\
& 100 & $\mathrm{~N} / \mathrm{A}^{a}$ & 393 & 677 & 392 & 100 & 93
\end{tabular}

${ }^{a}$ Not measurable due to pore collapse. ${ }^{b}$ Exothermic onset (DSC). ${ }^{c}$ Area under the exotherm. ${ }^{d}$ Onset of decomposition (TGA). ${ }^{e}$ Mass loss after ramping to $700{ }^{\circ} \mathrm{C}$.

this temperature range, the aerogels containing less than 50 mol\% of 2 absorb heat (Fig. 5(a)). This can be attributed to the insulating nature of the aerogels when arranged in a porous structure. Introducing pores decreases the thermal conductivity dramatically due to the low conductivity of the gaseous medium in the pores. This is shown in the drop off heat flow in the 0 through $30 \mathrm{~mol} \%$ aerogels above $400{ }^{\circ} \mathrm{C}$. In this temperature range, xerogel samples did not exhibit any heat absorption and is attributed to the lack of a porous structure (Fig. 5(b)). Overall, the xerogel samples have a larger enthalpy of decomposition with respect to their aerogel counterparts. It is well established that the manner in which sol-gels are dried can affect the physical and mechanical properties of the resulting materials. ${ }^{16,26}$ With the ambiently dried xerogel materials being glasslike and denser than their aerogel counterparts, they dissipate heat less effectively, resulting in higher enthalpies of decomposition. The characterization data of the sol-gels is summarized in Table 2 .

\section{Conclusions}

Utilizing the reactive nature of PFCP towards nucleophilic addition, a new fluorocyclic silane monomer (2) was synthesised in high yield and used in the preparation of the first known fluorocyclic aerogels and xerogels. In order to study the effects of the monomer on the properties of the sol-gel materials, the mol\% of 2 was systematically varied. Analysis by SEM and BET surface area measurements indicated that only aerogels with 0,20 , and 30 mol\% of 2 contained pores with measureable dimensions. Thermal analysis of the sol-gel materials showed that as the mol\% of 2 was increased, the aerogels and xerogels demonstrated an increase in the enthalpy of decomposition. Furthermore, the use of a fluorocyclic monomer versus a linear PFC produces sol-gel materials with increased thermal stability. Furthermore, accelerated thermal degradation was observed in those gels were the pores had collapsed as condensed medium dissipates heat less efficiently. This study demonstrates the ability to successfully introduce organo-fluorine moieties in moderately high loadings compared with previously published work that also demonstrate improved thermal stability. ${ }^{11,12,16,24}$ 


\section{Acknowledgements}

This paper was supported by the Air Force Office of Scientific Research (AFOSR). Additional support was provided by the Air Force Research Laboratory (AFRL), Aerospace Systems Directorate, Edwards Air Force Base, CA and the Air Force Research Laboratory, RWME, Eglin Air Force Base, FL. A. R. J. and J. M. were supported through the National Research Council (NRC) Post-Doctoral Research Associate Program. The ${ }^{29} \mathrm{Si}$ NMR was generously provided by Prof. David Y. Son at Southern Methodist University. A. R. J. acknowledges funding for this work made available by AFOSR, sponsored by the U.S. Air Force Academy under Agreement FA7000-16-2-0009.

\section{Notes and references}

1 L. L. Hench and J. K. West, Chem. Rev., 1990, 90, 33.

2 R. Ciriminna, A. Fidalgo, V. Pandarus, F. Béland, L. M. Ilharco and M. Pagliaro, Chem. Rev., 2013, 113, 6592.

3 A. C. Pierre and G. M. Pajonk, Chem. Rev., 2002, 102, 4243. 4 J. Zha and H. Roggendorf, Adv. Mater., 1991, 3, 522.

5 D. Avnir, T. Coradin, O. Lev and J. Livage, J. Mater. Chem., 2006, 16, 1013.

6 A. Walcarius, Chem. Mater., 2001, 13, 3351.

7 H. Schafer, B. Milow and L. Ratke, RSC Adv., 2013, 3, 15263. 8 J. G. Reynolds, P. R. Coronado and L. W. Hrubesh, J. NonCryst. Solids, 2001, 292, 127.

9 R. Ciriminna and M. Pagliaro, Analyst, 2009, 134, 1531.

10 A. Roig, E. Molins, E. Rodriguez, S. Martinez, M. MorenoManas and A. Vallribera, Chem. Commun., 2004, 2316.

11 T. M. Tillotson, K. G. Foster and J. G. Reynolds, J. Non-Cryst. Solids, 2004, 350, 202.
12 S. A. Lermontov, N. A. Sipyagina, A. N. Malkova, A. V. Yarkov, A. E. Baranchikov, V. V. Kozik and V. K. Ivanov, RSC Adv., 2014, 4, 52423.

13 Y. Duan, S. C. Jana, B. Lama and M. P. Espe, J. Non-Cryst. Solids, 2016, 437, 26.

14 J. P. Giesy and K. Kannan, Environ. Sci. Technol., 2001, 35, 1339.

15 J. M. Conder, R. A. Hoke, W. d. Wolf, M. H. Russell and R. C. Buck, Environ. Sci. Technol., 2008, 42, 995.

16 L. Zhao, B. J. Clapsaddle, J. H. Satcher, D. W. Schaefer and K. J. Shea, Chem. Mater., 2005, 17, 1358.

17 S. Brunauer, P. H. Emmett and E. Teller, J. Am. Chem. Soc., 1938, 60, 309.

18 M. Kruk and M. Jaroniec, Chem. Mater., 2001, 13, 3169.

19 M. A. B. Meador, A. S. Weber, A. Hindi, M. Naumenko, L. McCorkle, D. Quade, S. L. Vivod, G. L. Gould, S. White and K. Deshpande, ACS Appl. Mater. Interfaces, 2009, 1, 894. 20 S. T. Iacono, A. R. Jennings, US Pat., 15074128, 2016.

21 K. M. Knauer, A. R. Jennings, A. N. Bristol, S. T. Iacono and S. E. Morgan, ACS Appl. Mater. Interfaces, 2016, 8, 12434.

22 M. Abboud, M. Turner, E. Duguet and M. Fontanille, J. Mater. Chem., 1997, 7, 1527.

23 G. St-Pierre, A. Chagnes, N.-A. Bouchard, P. D. Harvey, L. Brossard and H. Ménard, Langmuir, 2004, 20, 6365.

24 S. A. Lermontov, N. A. Sipyagina, A. N. Malkova, A. V. Yarkov, S. G. Vasil'ev, N. P. Simonenko, A. E. Baranchikov and V. K. Ivanov, RSC Adv., 2016, 6, 80766.

25 S. Lermontov, A. Malkova, L. Yurkova, E. Straumal, N. Gubanova, A. Baranchikov, M. Smirnov, V. Tarasov, V. Buznik and V. Ivanov, J. Supercrit. Fluids, 2014, 89, 28.

26 H. Satha, K. Atamnia and F. Despetis, J. Biomater. Nanobiotechnol., 2013, 4, 17. 